\title{
Declaración de Teotihuacan (2000)
}

Cumbre Indígena Continental Teotihuacan

Cumbre Indígena Continental Teotihuacan, 28 al 30 de octubre de 2000

La Cumbre Indígena Continental reunida al pie del Centro Ceremonial de Teotihuacan, y al cumplirse el Segundo Milenio del calendario Gregoriano y los 508 años de la invasión europea, los delegados y delegadas indígenas representando a los diversos Pueblos Originarios del continente:

\section{DECLARAMOS Y REAFIRMAMOS ANTE EL MUNDO LO SIGUIENTE:}

Los Pueblos Indígenas de América reafirmamos nuestros principios de espiritualidad comunitaria y el inalienable derecho a la Autodeterminación como Pueblos Originarios de este continente. En esta era de globalización económica impuesta por los grandes capitales de las empresas trasnacionales y los llamados países industrializados, que amenaza nuestra existencia misma, los Pueblos Indígenas de los diferentes Estados que vivimos en el continente, estamos organizados y aunando esfuerzos de coordinación y solidaridad para salvaguardar los sagrados derechos de nuestros Pueblos para las generaciones futuras.

\section{CONSIDERANDO:}

Que, si bien ha habido algunos logros en materia de derechos Indígenas a nivel de acuerdos internacionales, los llamados Estados Lati- 
noamericanos y Anglosajones del Norte, continúan negando nuestros derechos y libertades fundamentales. Que, si bien el convenio 169 de la OIT adoptado hace mas de once años, reconoce varios de nuestros derechos, la mayoría de los Estados gobiernos, no lo han ratificado, y aquellos que lo han hecho, han tomado medidas para debilitar sus contenidos y el espíritu del mismo.

Que, el Proyecto de Declaración de los Derechos de los Pueblos Indígenas en la ONU, después de 16 años de constante lucha y esfuerzos de los representantes Indígenas, los estados coloniales siguen negando la aprobación de la misma.

Que, el proyecto de Declaración Americana de los Derechos de los Pueblos Indígenas en la Organización de Estados Americanos (OEA), sus actuales contenidos no incluyen los derechos y libertades fundamentales de los Pueblos Indígenas. Esto es una consecuencia directa de ser un instrumento elaborado desde la visión de los Estados, y sin la participación plena de los representantes de los Pueblos Indígenas.

Que, si bien el Convenio sobre la Diversidad Biológica reconoce ciertos derechos Indígenas, en su articulo $8 \mathrm{~J}$ del mismo, en la practica las companias trasnacionales con el acuerdo de los gobiernos, han intensificado la política de saqueo y expropiación de los recursos naturales y la Biodiversidad que se encuentran en los territorios Indígenas, causando destrucción ecológica y afectando los derechos colectivos de nuestros Pueblos.

La idea de un Foro Permanente para los Pueblos Indígenas en la ONU, contó con el legítimo apoyo de los indígenas, sin embargo en el transcurso del proceso, su mandato se ha debilitado y se ha excluido el concepto de Pueblos Indígenas, lo que no satisface plenamente las aspiraciones indígenas.

Que, la política financiera impuesta por el Fondo Monetario Internacional, FMI, el Banco Mundial y el Banco Interamericano de Desarrollo (BID), con la complicidad de los gobiernos, han impuesto políticas de ajuste para beneficiar el consumismo desmedido de los

países del Norte. Esto ha acentuado la dependencia, la opresión y el empobrecimiento de los Pueblos Indígenas y los sectores populares. 
Que, a pesar de instaurarse las llamadas democracias en el continente, la violación a los Derechos Humanos, al derecho a una vida digna, la libertad y el derecho a definir nuestro propio destino como Pueblos diferentes, reconocidos en la Declaración Universal de los Derechos Humanos, estos siguen siendo negados por los estados coloniales.

Que, los Acuerdos de Paz en Guatemala y San Andrés en Chiapas (México) han sido solo promesas de justicia para los Pueblos. La represión en contra de líderes Indígenas continua como ser: Honduras, Chile, México, Perú, Bolivia, Guatemala. El Plan Colombia apoyado por Estados Unidos traerá más represión, militarización y sufrimiento para los Pueblos Indígenas y no Indígenas en Colombia.

\section{POR LO TANTO:}

Los delegados Indígenas reunidos en esta Cumbre Continental, REAFIRMAMOS:

1. Los indígenas seguimos estando guiados por nuestras normas culturales, espirituales, lingüísticas e históricas, por tanto, seguimos siendo Pueblos Indígenas, con derechos imprescriptibles e inalienables que le asisten a todos los Pueblos del mundo.

2. Los Pueblos Indígenas desarrollamos nuestra cultura en determinados espacios territoriales, en donde se han establecido vínculos espirituales, lingüísticos, que conforman nuestra identidad milenaria. Sin embargo, hemos sido despojados en el proceso de conformación de los Estados Nacionales. Los territorios, los recursos de la biodiversidad constituyen derechos inalienables e imprescriptibles para los Pueblos Indígenas.

3. Los Pueblos Indígenas, reafirmamos el principio y el derecho a la Libre Determinación, considerando que este derecho representa la columna vertebral de todos los otros derechos que nos asisten. 


\section{DEMANDAMOS:}

1. Exhortamos a los Gobiernos del mundo a que apoyen y adopten el Proyecto de Declaración de los Derechos de los Pueblos Indígenas de Naciones Unidas, en el marco del Decenio Internacional de los Pueblos Indígenas del Mundo. En vista a que el Programa del Decenio, es un compromiso de los gobiernos ante la comunidad internacional.

2. Llamamos a los Gobiernos que conforman la Organización de Estados Americanos (OEA), a que reactiven el dialogo sobre el Proyecto de Declaración de los Derechos de los Pueblos Indígenas, y que el Grupo de Trabajo convoque a una nueva sesión sobre el instrumento. Asimismo, se garantice la más amplia participación de los Pueblos Indígenas en el proceso, potenciando el Comité Indígena como forma de enlace con las organizaciones interesadas.

3. Que los Estados renuentes a la ratificación del Convenio 169 de la OIT, ratifiquen el instrumento como una señal de su voluntad política en la protección y reconocimiento de los derechos de los Pueblos Indígenas.

4. Que los Estados reconozcan a los Pueblos Indígenas y sus derechos, en sus constituciones políticas, garantizando su participación, protección de su tierra y territorio y asegurando el derecho a decidir su propio destino.

5. La Asamblea general de delegados decidió continuar la coordinación de la unidad indígena continental en una próxima Cumbre que se realizara en Ecuador en el año 2001, organizada por la Confederación de Nacionalidades Indígenas de Ecuador (CONAIE) con el apoyo de todas las organizaciones participantes en esta Cumbre. 
6. Esta Cumbre Indígena Continental hace un llamado fraternal y de unidad a todos los Pueblos Indígenas para fortalecer el proceso organizativo y de comunicación para que juntos podamos reconstruir un futuro mejor para generaciones venideras.

¡POR LA LIBREDETERMINACION DE LOS PUEBLOS INDIGENAS Y LA RESTITUCION DE SUS TERRITORIOS!

Firmado por 36 Organizaciones Indígenas de todo el Continente 